\title{
Research on the Blended Teaching of Mathematics in Military Academy Based on the Micro-lectures
}

\author{
Hongmei Pei ${ }^{1, a}$ and Xin Wang ${ }^{1, b}$ \\ 'Department of Basic, Dalian Naval Academy Liaoning, Dalian, China \\ ahongmei_005@163.com, b63180583@qq.com
}

Keywords: Micro-lectures; Blended teaching methods; Advanced mathematics; Military academy

\begin{abstract}
Mathematics is one of the most important basic courses in military academy, its traditional teaching methods have been unable to meet the era of big data cadets' personalized, diversified learning needs. This article makes a discussion on the blended teaching method that based on the micro-lectures. On the basis of analyzing the characteristics of the micro-lectures and the blended teaching method, the design of the blended teaching method based on the micro-lectures in the mathematics teaching of the military academy is put forward.
\end{abstract}

\section{Introduction}

Advanced mathematics is one of the most important courses in military academy, which is not only the basic of cadets' learning the following courses, but also an important way to train cadets to analyze problems and solve problems. Throughout the military academy of advanced mathematics course teaching mode, we can find that most of them are still in the traditional teaching mode of theory based, however, this is contradicted against the cadets of the era of big data for personalized, diversified learning demand, and there is an urgent need for change of information technology in education. While the micro-lectures are in line with the cognitive characteristics of cadets with their characters of short, focused, and pay attention to interaction. "Miniature" way of learning is much more in line with the cadets' network learning characteristics, micro-lectures concept applied to blended teaching method, to improve learning efficiency has become a new development trend. How will this concept into the military academy of mathematics teaching, and how to carry out blended teaching that combined micro-lectures and the traditional teaching methods, which requires combined with the characteristics of mathematics courses system design. In this paper, we take the Advanced Mathematics as an example to explore the blended teaching mode that based on micro-lectures.

\section{Micro-lectures and Their Characteristics}

The prototype of the micro-lectures is 60s course proposed by American professor Leroy A. McGrew [1]. The micro-lectures that we called now are proposed by David Penrose, who is the senior teaching designer of New Mexico San Juan college of America. According to the actual situation of our country, teacher $\mathrm{Hu}$ Tiesheng firstly proposed the comparatively systematic concept of micro-lectures in our country in 2010. With its advantages of short teaching time, refined teaching content, small capacity, resources structure "situation oriented", theme highlighted, original creation, feedback timely, strong pertinence etc. [2], micro-lectures has aroused widespread concern in the education sector. Compared with the traditional courses, it has the following characteristics:

(1) Compared with the traditional courses from perspective of the teaching content, both of the design and production of micro-courses are centered on a goal, which has a clear theme, and the teaching content is of the essence, which is also gives prominence to the key points of knowledge.

(2) Compared with the traditional courses from perspective of the teaching way, the micro-lectures have many ways, for example, video, audio etc, the teaching ways are flexible and diverse. 
(3) Compared with the traditional courses from perspective of the teaching time, usually the time of micro-lectures are 8-20 minutes, thanks to the short time of teaching, the cadets' attention are focused, and high learning efficiency achieved.

(4) Compared with the traditional courses from perspective of the teaching effect, the form of micro-lectures is novel, which can arouse the cadets' study interest.

Due to the characteristics of micro-lectures, teachers can apply micro-lectures to the blended teaching by designing properly. Traditional teaching has its weak points, which is to say that traditional teaching can't provide learning consolidation and feedback, while by applying micro-lectures to the blended teaching, not only the traditional teaching's weak points can be covered well but also the micro class advantages can be used thus to enhance the learning effect of cadets.

\section{Blended Teaching Method}

What Does Blended Teaching Method Mean? Blended learning is not a new teaching methods or theories, but with the development of education information, so it has been paid more attention. Some scholars have expounded the blended teaching method from different angles: Curtis bunker thinks that blended teaching method is combined with face to face teaching and computer aided teaching; Professor Li Jiahou thinks that blended teaching is to optimize the selection and combination of all elements of teaching, in order to achieve the teaching goal [3]. It is not difficult to find, the connotation of blended learning is very wide: from the perspective of form, blended teaching is not only a combination of online and offline, but the integration of different teaching theories, teaching methods and evaluation way; from the perspective of resource, blended teaching organically combines video teaching resources, supplementary teaching resources, multimedia resources and learning resources; from the effective point of view, blended teaching reflects the cadets as the main body, and teachers-dominated double subject education thought, to teach as the center and to learn for the integration of teaching mode. It advocates combining the advantages of traditional teaching and digital teaching advantages, the advantages of complementary being emphasized, so as to achieve better teaching results [4].

Why should Advanced Mathematics Use the Blended Teaching Methods? Advanced mathematics is the basic course of Military Academy. In the course of teaching, there are some basic problems:

First, it has a high degree of abstraction, blindly using traditional teaching mode to make cadets feel dull, lose interest in learning, and learning effect is greatly reduced;

Second, the level of cadet's learning, knowledge structure is different from each other, and according to the arrangement of courses, teaching speed is the rhythm that makes the moderate degree cadets can keep up with. Therefore, teaching process will cause some cadets can't keep up; some cadets "do not have enough to eat".

In order to solve these problems, in the teaching we will also make use of modern education technology, such as the use of PPT add some video or instance to attract cadets' attention, arouse cadets' interest, but effect is not lasting. And continued to micro-lectures auxiliary blended teaching can solve this problem very well. In the teaching, how to combine the existing resources and characteristics of military academy to carry out blended teaching based on micro-lectures, this is an enormous challenge that every military academy teachers face.

\section{Design of the Blended Teaching Method Based on the Micro-lectures in the Mathematics}

Clear Teaching Objectives. Before teaching, teachers must first clear teaching objectives, to optimize the teaching content and to determine the teaching method according to the teaching objectives:

(1) What should cadets learn from this teaching? To what extend should they learn? 
(2) What is the consolidation of knowledge during the course of the teaching and what is the connection between these knowledge and the following courses? To what knowledge this course is prepared for?

(3)To cultivate cadets which ability, combined with what knowledge, skills of teaching to train?

(4) In the content of this course, what are the typical mistakes of the cadets, how to correct these errors and practices?

To answer these questions, teachers should not only be familiar with the knowledge system of the courses they teach, understand cadets' knowledge structure, knowledge level, but also have to know the knowledge that can be used by cadets in the following courses. After clearing teaching objectives, teachers should focus on the cultivation of cadets' ability to make specific teaching plan and teaching measures.

Optimize the Teaching Content. After defining the teaching goal, according to the teaching target classification of teaching content, determine what knowledge is suitable to use the micro-lectures teaching mode, which is suitable to use the traditional way of teaching; And which is suitable for the production of micro-lectures before class interest guide, which is suitable for the teaching and discussion in class, which is suitable for the summary in after using the micro-lectures. For example, there are many concepts and theorems in Advanced Mathematics, generally concepts and theorems in the history of mathematics has its background, or has its practical significance in life, the math teachers can combine these together to make a micro-lectures, through micro-lectures video that allows cadets to have a systematic learning, which can not only arouse interest in cadets, let cadets understand the development and the history of mathematics, but also make the abstract concepts become intuitive and specific, deepen the cadets' understanding of knowledge. Here we list some concepts, theorems and some related mathematical problems that suitable for micro-lecture teaching in Table 1.

Table 1 Examples of related problems of typical concepts and theorems

\begin{tabular}{|c|c|}
\hline $\begin{array}{c}\text { Concepts and theorems of Advanced } \\
\text { Mathematics }\end{array}$ & $\begin{array}{l}\text { Relevant background and practical } \\
\text { problems }\end{array}$ \\
\hline $\begin{array}{c}\text { definition of the limit of sequence of } \\
\text { number } \\
\text { differential mean value theorem } \\
\text { concept of curvature } \\
\text { Taylor formula } \\
\text { the calculus basic formula } \\
\text { geometric application of definite } \\
\text { integral }\end{array}$ & $\begin{array}{l}\text { cutting circle method and Zeno paradox } \\
\text { speed limit of expressways } \\
\text { railway curve design problem } \\
\text { plane landing curve problem } \\
\text { the history of calculus } \\
\text { paradox of Gabriel horn }\end{array}$ \\
\hline
\end{tabular}

Design Teaching Mode. Before teaching, the teachers must design the entire course teaching mode firstly. This requires teachers be familiar with Advanced Mathematics knowledge system and the knowledge structure of cadets. According to the characteristics of curriculum knowledge points of every chapter, Advanced Mathematics is divided into theory type and application type, according to the difficulty level and the importance of professional competence training, Advanced Mathematics is divided into teaching type and self-study type. For the theory and teaching type, the teachers' classroom based on teaching, and emphasize the interaction between teachers and cadets; For the application type and self-study type, mainly it is micro-lectures and discussion learn. Apart from the teaching method classification, micro-lectures should also be divided into three types, which are before class type, in class type and after class type according to the teaching objectives. Different settings can play different roles, before class type can be combined with the task of learning to shape a guidance on learning, which is, to help the cadets preview the key, difficult points and the knowledge that need to be learn in advance. In class type can help cadets to solve the difficulties, key points, error prone and easily confused points, to complete the internalization of knowledge, to make the cadets to maintain and strengthen their learning interest. Micro-lectures used after class can help students review and 
consolidate the key points and difficulties, doubts, error prone, easy to confuse points, prompt the extended learning, promote the migration of application, leads to subsequent learning. When teaching, the teachers should not only according to teaching contents to determine the micro-lectures and the traditional teaching modes, but also according to the knowledge structure of the cadets, the mental state and time distribution to arrange micro-lectures and traditional teaching modes.

\section{Create Micro-lectures}

The first part above, we analyzed the characteristics of micro-lectures, micro-lecture is famous because of its short time, its fine teaching content, which is its advantages, but also its disadvantages. A single, isolated micro-lecture will make knowledge point be cut into several parts, and be fragmentation, thus an isolated information island shaped, in which situation cadets will not well digest knowledge completely. Although there is a way to remedy by using traditional classroom instruction, however, if using micro-lectures frequently or if there is no connection among the micro-lectures, the cadets will loss fresh easily, and will have "aesthetic fatigue." If we can in accordance with the order and principles to list special core knowledge points one by one, and create a series of micro-lectures around these core knowledge points, then the isolated micro-lectures can be associated and can be systematic. A special topic, a series of micro-lectures of a course called micro courses. Teachers can focus on the specific teaching content to create a series of micro courses, for example, we can set up such a micro course on the contents of the second chapter of the "Advanced Mathematics":

Table 2 Micro-course

\begin{tabular}{c|l}
\hline micro course theme & \multicolumn{1}{c}{ Core micro course content } \\
\hline The historical & $\begin{array}{l}\text { 1.Two major scientific problems faced in the 16, 17 } \\
\text { century } \\
\text { 2.Second crises in the history of Mathematics } \\
\text { development of the } \\
\text { Calculus }\end{array}$ \\
& $\begin{array}{l}\text { 3.Mathematical history of the concept of limit } \\
\text { 4.The origin of derivative and differential symbol } \\
\text { 5.Leibniz's primary error }\end{array}$ \\
\hline
\end{tabular}

After making the micro courses systematic, cadets can do the course learning by follow the "cut up $\rightarrow$ connect $\rightarrow$ integrate" knowledge create order, and achieve the knowledge integration and innovation finally.

\section{Summary}

This paper discussed the blended teaching mode based on micro-lectures of Advanced Mathematics, and proposed the blended teaching method's design and mode in the teaching process of Advanced Mathematics. We let micro courses get involved in the traditional teaching mode thus to create more chances to make cadets display great initiative in learning, besides, mathematics curriculum's teaching mode get innovated, the diversification of teaching content achieved.

This paper proposed blended teaching mode based on micro-lectures only to mathematics teaching of those Military Academy which take Advanced Mathematics as the main, whether applicable in other courses teaching remains to be further verified; Also the teaching model's effectiveness of promoting the cadets' learning performance also need to further practice to verify.

\section{Acknowledgements}

This work was supported by Naval teaching achievement project, which is "The innovation and practice of 'effective teaching' of mathematics course in Military Academy". 


\section{References}

[1] Zheng Xiaojun, Zhang Xia, Six questions and response of Micro-lectures [J], Modern Distance Research, 2014, 2, pp. 48-54.

[2] Ang Juan, Yu Xin, Shui Miao, Analysis of micro-lectures design strategy based on flipped classroom [J], Journal of Chongqing University of Science and Technology (social science edition), 2014, 12, pp. 161-166.

[3] He Bo, Lan Guoshuai, Wang Zuyuan, Zhang Yichun, and Research on the application of micro-lectures teaching based on blended learning [J], China Education Information, 2014, 20, pp. $15-17,24$.

[4] Gao Yufeng, Zhou Zhiwen, The application of blended teaching method in the teaching reform of advanced algebra course [J], Journal of Tonghua Normal University, 2012, 33, pp. 56-57. 